\title{
Infrastructure Stakeholders' Perspective in Development and Implementation of New Structural Health Monitoring (SHM) Technologies for Maintenance and Management of Transportation Infrastructure
}

\author{
Dilendra Maharjan $^{1 *}$, Marlon Agüero ${ }^{1}$, Chris Lippitt ${ }^{2}$, and Fernando Moreu ${ }^{1}$ \\ ${ }^{1}$ Department of Civil Engineering, Construction and Environmental Engineering, MSC01 1070, 1 University of New Mexico, \\ Albuquerque, NM 87131 \\ ${ }^{2}$ Department of Geography and Environmental Studies, University of New Mexico MSC 01 1110, 1 University of New Mexico
}

\begin{abstract}
Infrastructure is the backbone of the US economy and a necessary input to every economic output [1]. The cost of infrastructure maintenance and management demands significant expense for government and private companies. Infrastructure owners want to increase efficiency and improve their bottom-line from existing infrastructure rather than building new ones [2]. One of the significant challenges for the engineering community has been adopting new technologies such as low-cost wireless smart sensors, augmented reality, Unmanned Aerial System (UAS)-based Structural Health Monitoring (SHM). To receive first-hand insight from infrastructure owners, industry professionals and researchers, a workshop entitled 'Infrastructure, Maintenance and Management Using New Technology' was conducted in Fort Worth, Texas. In this paper the findings from the workshop are discussed. Stakeholders highlighted safety of the bridge inspectors as the priority in the maintenance and management work. Based on the findings of this workshop it now clear that adopting new technologies leads to higher safety for field inspectors. Key aspects include importance of new technologies for obtaining actionable data for maintenance and management, owner's perspectives on development of future technologies, current research progress and challenges faced by infrastructure industry in implementing new technologies are presented.
\end{abstract}

\section{Introduction}

American Railroads carry $40 \%$ of total freight ton-miles in United States over 100,000 bridges spanning over 140,000 miles of rail track [3]. Railroad companies are private entities responsible for maintaining their own infrastructure as mandated by Federal Railway Administration (FRA). It is also in their best interest to keep their railway infrastructure up to the serviceable standard to avoid any type of delay in the service. This can be achieved by Structural Health Monitoring (SHM) of the infrastructure [4]. Past research studies have also highlighted the importance of SHM in holistic management of infrastructure throughout the lifecycle management of infrastructure [5]. Basically, SHM of civil infrastructure can prolong the usable life of a structure, decrease total life-cycle cost, and most importantly, improve public safety [9]. With the advent of new technologies, the field of SHM is being rapidly revolutionized. However, railroad industries are yet to adopt new technologies for inspection, maintenance and management of the existing infrastructure. As there are numerous opportunities with using the technologies, it is equally important to consider the challenges faced. Since railroad owners are decision makers for their infrastructure, it is essential to know what they prioritize in maintenance, repair and management. The workshop was a means to gather major stakeholders in railroad industry and seek their perspective for future research needs regarding new technologies that can be adopted by the industry practitioners. Thus, the workshop was conducted with railroad industry stakeholders to identify the future opportunities and associated challenges regarding identification, development and applicability of new technologies.

As a part of the development and implementation of a working technology for inspection, authors developed an application in Augmented Reality headset Microsoft HoloLens to test the usability of such technology in the real-world application of inspection and maintenance. The application was tested in a laboratory setting and worked as intended for recording and visualizing information that was value to the inspector. Since the work is in progress, in near future, we will be testing the application in real field where bridge inspector will use the application to visualize information as opposed to using traditional form of documentation for viewing past inspection reports.

\footnotetext{
* Corresponding author: dmaharjan@unm.edu
} 


\section{Motivation}

According to Byers and Otter [6], a cycle of fertile research production versus a sterile research environment has alternated over the last 70 years. The NSF funded workshop at UIUC of 1987 can be considered a corner stone in identifying research needs in railroad industry. That workshop generated research topics that satisfied industry needs for a period of about 20 years [2]. This 20-years cycle has passed, so a new workshop between railroad bridge experts is due. The workshop conducted in Fort Worth was a coordinated effort of multiple stakeholders from funding agency Tran-SET, federal government agency, FRA, infrastructure owners, industry professionals, university researchers and students. Like the workshop in 1987, authors believe that this workshop can identify, and advance future research needs primarily focusing in SHM technologies.

A workshop-based study is an effective tool for understanding perspectives from a multitude of participants. To compare the present and future needs for developing technologies for SHM works, workshops can play an important role in bringing attention to the most pressing issues regarding implementation of technologies for real world applications. The workshop strives to identify three main interest areas where research effort could be advanced.

I. Challenges for infrastructure maintenance and management.

II. Challenges for implementing new technologies, sensor, applications and algorithms.

III. Frontier between future need and technologies.

\section{Findings}

At the beginning and at the end of the workshop, participants were asked about their level of confidence in introducing new technologies in future infrastructure maintenance and management work. Before the workshop, most participants were slightly confident to use the new technologies, as shown in Figure 14. The median confidence level before workshop was "Fairly Confident" (3 out of 5) and after the workshop was "Well Confident" (4 out of 5). More specifically, as many as $18 \%$ of the workshop participants were highly confident to introducing new technologies in their daily activities. After the workshop, the participants who were highly confident to use new technologies in maintenance and management of infrastructure doubled, reaching $36 \%$ of the responses. The results from Figure 14 show the effectiveness of workshop in sharing knowledge and perspectives towards growing optimism towards using new technologies for infrastructure maintenance and management.

Participants were also asked about their preference between Inspection-centered and Network-centered technologies. Inspection centered technologies focused in the area where technologies could be developed to empower the bridge inspector in inspection and monitoring works. These technologies are human- centered which basically deals with providing tools for identifying, measuring and quantifying as well as analyzing data on site. On the other hand, the Networkcentered technologies primarily deal with establishing an integrated system of sensing technologies at site for realtime monitoring. As shown in Figure 35, most of the participants favored Inspection-centered technologies over Networked-centered technologies. Development and implementation of new technologies that emphasize assisting bridge maintenance engineers and inspectors are prioritized by the industry. These technologies can be then integrated with the bridge management system. $33 \%$ of participants believed that both types of technologies should be developed together for integrated approach to infrastructure maintenance and management.

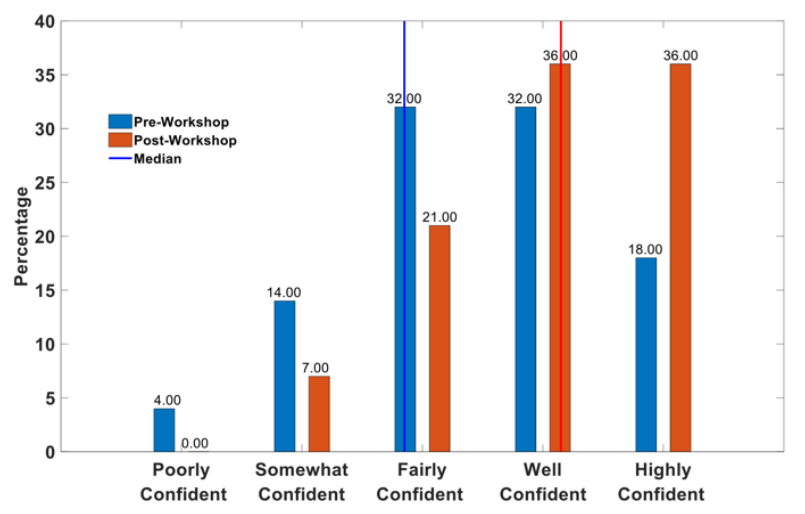

Fig. 1. Levels of confidence in using new technologies in future infrastructure maintenance and management work before and after the workshop.

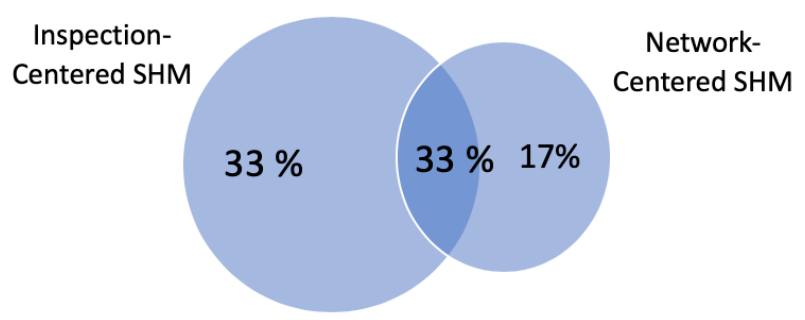

$17 \%$ opted for 'Others type of technology'

Fig. 2. Preference for type of technology for infrastructure management and maintenance.

The discussions in the workshop were primarily focused in identifying challenges related to research, development and implementation of new technology for maintenance and management of railroad infrastructure. To narrow down the topics discussed in the session, the workshop was divided into three sessions. Namely: Challenges for maintenance and management of railroad infrastructure, Challenges for implementation of new technologies and Frontier between future need and technologies. These sessions included interactive talk with each participant in the workshop. The key findings of the technical sessions are described below.

\subsection{Technical challenges}


Railroad operators want to lessen the impact on rail operations while conducting inspection, repair and maintenance. The slowing down of a moving train due to a dilapidated bridge has a lot of cost implications to the railroad owners. Hence, they want to conduct inspections that do not hinder the moving traffic. Non-contact SHM technologies such as AR, Drone based inspections, wireless sensors have shown to be one of the promising fields of research for academicians.

\subsection{Safety related challenges}

The railroad industry is meticulous in terms of ensuring safety to their operations. Safety of bridge workers carrying out the inspection, repair and maintenance work is also a major concern for the industry. Since the inspectors work in hazardous site conditions, often in extreme weather, railroad owners want to make sure that workers are equipped with all the possible safety gear.

\subsection{Education and trainings}

In the workshop, railroad owners expressed their concern regarding lack of technical exposure of the rail industry workforce. The wide generational gap between senior railroad staff members and new employees has worsened the knowledge transfer mechanism in rail industry. The new generation of employees trained to do critical tasks of inspection and repair are often easily distracted at work.

\subsection{Technological advancement}

Researcher and railroad professionals in the workshop stated the current scenario for advancing technology for infrastructure management and maintenance in railway industry. Remote bridge sensing inspection along with real-time information transfer from job site to the decision makers were two possible areas where professionals saw significant value for the industry. The ability to inspect inaccessible components of the bridge has also been the top research priority of the industry where the search for new technology is expected to yield new progress.

Augment Reality (AR) for Infrastructure Inspection: Based on the findings of workshop authors developed a novel method of visualizing inspection data using Augment Reality headset Microsoft HoloLens. Having access to information is critical in time constrained situation, which can be especially important in disasters management, and emergencies environments, but also beneficial for daily operations related to management and decisions. Modern technology can provide many solutions to this problem with developments in areas such as Augmented Reality, which can help by providing quick and visual information about the current state of infrastructure [7, 8]. This research includes the development of an Augmented Reality application to integrate the barcode scanner as a USB (Human Interface Device) HID device to be connected to the Microsoft HoloLens. This application allows to read the decoded string of the barcode and program and then program an output to get visual information. The value of the work of AR in infrastructure management is bringing the ability of real-time display of information across time and space to the user (inspector) not possible before.

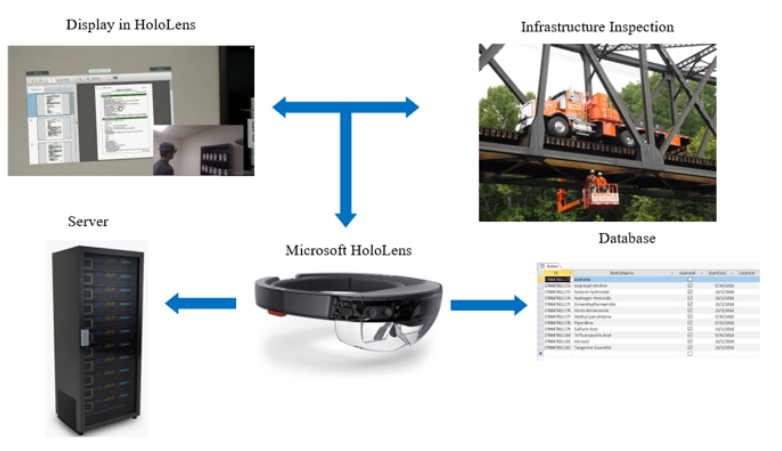

Fig. 3. Augment Reality headset (Microsoft HoloLens) was used to build a system architecture where inspectors could go to site, connect to the remote server and view information.

\section{Conclusions}

Infrastructure owners are concerned about the increasing cost of maintenance and management of aging infrastructure, and they believe an increasing utilization of new technology can significantly reduce the cost. The participants at the workshop believed that validation of new technologies could help industry professionals adopt new technologies sooner than otherwise. Railway industry stakeholders are familiar with the research and development of new technologies for SHM applications. They are seeking actionable data from the new technology developed by the researcher; data that can be used objectively to verify the state of the infrastructure. Railroad owners highlighted safety of the bridge inspectors as the priority in the maintenance and management work. Moreu [2] also discussed the vulnerability faced by bridge inspectors while inspecting structural elements of a high truss bridge. Developing techniques for remote sensing was one of the most promising emerging fields within SHM where frontiers can be expanded to help bridge inspectors avoid hazardous working conditions. Development of Augmented Reality for structural inspection could be promising technology for speed inspection works. Based on the findings of the workshop stakeholders are eager to adopt new technologies if they provide reliable data for the field inspectors.

\section{References}

1. ASCE (2016). Failure to Act: Closing the Infrastructure Investment Gap for America's Economic Future. Prepared by Economic Development Research Group Inc, 2016 https://www.infrastructurereportcard.org/wpcontent/uploads/2016/05/2016-FTA-Report-Closethe-Gap.pdf 
2. Moreu, F. and Lafave, J.M. (2012). Current Research Topics: Railroad Bridges and Structural Engineering. NSEL Report Series, Report No. NSEL-032, October 2012

3. Ozdagli, A., Liu, B. and Moreu, F. (2018). Measuring Total Transverse Reference-Free Displacements for Condition Assessment of Timber Railroad Bridges: Experimental Validation.

4. Karbhari, V.M. and Ansari, F. (Eds.). (2009). Structural health monitoring of civil infrastructure systems. Elsevier.

5. Farrar, C.R. and Worden, K. (2007). An introduction to structural health monitoring. Philosophical Transactions of the Royal Society of London A: Mathematical, Physical and Engineering Sciences, 365(1851), 303-315.

6. Byers, W.G. and Otter, D. (2006). Reducing the Stress State of Railway Bridges with Research: Researchers at TTCI Stay on Top of Railway Bridge Research to Ensure Safety, Cost Effectiveness and Maximum Life Cycle of Materials. Railway Track and Structures: RT \& S, 1953, Chicago: Simmons Boardman Pub. Corp., February.

7. De Marchi, L., Ceruti, A., Marzani, A., and Liverani, A. (2013). Augmented reality to support on-field post-impact maintenance operations on thin structures. Journal of Sensors.

8. Zhou, Y., Luo, H., and Yang, Y. (2017). Implementation of augmented reality for segment displacement inspection during tunneling construction. Automation in Construction, 82, 112121.

9. Rice, J. A. and Spencer, Jr., B. (2009). "Flexible Smart Sensor Framework for Autonomous Fullscale Structural Health Monitoring." NSEL Report Series, Report No. NSEL-018, August 2009 